\title{
The presence of obesity paradox in Greek patients with chronic heart failure
}

\author{
This article was published in the following Dove Press journal: \\ Pragmatic and Observational Research \\ 21 September 2017 \\ Number of times this article has been viewed
}

\author{
Efstratios Vlaras' \\ Konstantinos \\ Giakoumidakis ${ }^{2}$ \\ Nikolaos V Fotos' \\ Anastasia A \\ Chatziefstratiou' \\ Hero Brokalaki' \\ 'Department of Nursing, School \\ of Health Sciences, National \& \\ Kapodistrian University of Athens, \\ Athens, Greece; ${ }^{2}$ Cardiac Surgery \\ Intensive Care Unit, "Evangelismos" \\ General Hospital of Athens, Athens, \\ Greece
}

Purpose: To investigate the effect of body mass index (BMI) values on 1- and 2-year mortality rates in patients with chronic heart failure (HF).

Patients and methods: We conducted a retrospective cohort study of 112 patients with confirmed HF who visited the HF outpatient unit of a tertiary hospital of Athens, Greece, during a 5-month period (December 2012 - April 2013). These patients were assigned to four groups based on their BMI category. Data collection was carried out through a review of the medical patient records and the filling in of a structured questionnaire, including information on the demographic and clinical patient variables. Additionally, 1- and 2-year patient mortality was recorded. The statistical significance was two-tailed, and $p$-values of less than 0.05 were considered significant. The statistical analysis was performed with Mann-Whitney $U$ test, $\chi^{2}$ test, and Student's $t$-test using the SPSS software (IBM SPSS 21.0 for Windows).

Results: Obese patients had significantly lower 1-year (13\% vs 34.6\%, $p=0.039)$ and 2 -year ( $4 \%$ vs $21.4 \%, p=0.022)$ mortality rates compared with those with normal BMI values. Additionally, we found clinically and not statistically significant lower mortality in overweight and obese patients, when compared with normal BMI and overweight patients, respectively.

Conclusion: Obesity paradox seems to be present in our study, translating to significantly lower long-term mortality rates of obese patients compared to those with normal BMI. The significantly higher left ventricular ejection fraction and hematocrit levels among obese HF patients could justify our study findings. Further research is needed due to the inherent weaknesses of BMI and the other study limitations.

Keywords: heart failure, mortality, obesity, retrospective studies

\section{Introduction}

Obesity is a major problem with a rapidly rising prevalence in the Western world. In the US, the age-adjusted prevalence of obesity in 2013-2014 was estimated to be 35\% and $40.4 \%$ among adult males and females, respectively, aged $\geq 20$ years old. ${ }^{1}$ Also, obesity is a well-known independent risk factor of cardiovascular disease, which can eventually lead to chronic heart failure (HF). ${ }^{2}$

Although obesity increases the risk of HF and has a negative impact on cardiovascular health, ${ }^{3,4}$ the protective effects of high body mass index (BMI) values in patients with confirmed HF diagnosis, translating into lower mortality rates, have been highlighted by several-high quality studies. ${ }^{5-8}$ In the currently available published research, many suggested mechanisms could be used to interpret this obesity paradox in HF patients, including the lower N-terminal pro-B-type natriuretic peptide levels; the higher ejection fraction; the reduced age; the tumor necrosis factor-alpha and endotoxin inhibition by lipids in circulatory blood; the higher metabolic reserve; the
Correspondence: Konstantinos

Giakoumidakis

Cardiac Surgery Intensive Care Unit,

"Evangelismos" General Hospital of

Athens, 45-47 Ipsilantou Street, 10676,

Athens, Greece

Tel +306973793489

Fax +302132041987

Email kongiakoumidakis@gmail.com 
more aggressive pharmaceutical therapy with better tolerance for drugs such as beta-blockers, aldosterone antagonists, and renin-angiotensin-aldosterone system inhibitors; the elimination of the hazardous influence of the malnutrition/ inflammation complex syndrome; and the lower sympathetic activation and norepinephrine levels in these patients. ${ }^{9,10}$

On the other hand, other studies have failed to show a significant association between BMI levels and longer HF patient survival, ${ }^{11-14}$ which is contrary to the previously mentioned literature studies that indicate the presence of the obesity paradox hypothesis. Indeed, according Colin Ramirez et al, ${ }^{15}$ HF patients with normal BMI values had significantly lower mortality compared with obese patients.

These controversial findings could be partly explained due to the potential limitation of BMI to fully assess the severity of obesity. Many authors call into question the reliability of BMI, supporting its inability to define body weight components such as fat mass, fat-free mass, and lean mass. ${ }^{3}$ Additionally, other variables, such as exercise capacity, nutrition, and physical action, could affect HF patient mortality, ${ }^{16-18}$ irrespective of BMI.

The aim of the present study was to investigate the effect of BMI on mortality of patients suffering from chronic HF. Our study is intended to add new knowledge on the controversial topic of obesity paradox hypothesis in patients with HF.

\section{Methods}

\section{Study design, variables, and participants}

A retrospective cohort study was conducted. The dependent variable (outcome) in our study was patient mortality (1- and 2-year mortality), and BMI was the independent variable. We, a priori, set the following inclusion criteria: 1) age greater than 18 years old and 2) documented diagnosis of HF with left ventricular ejection fraction $(\mathrm{LVEF}) \leq 45 \%$. Patients with recently establish acute coronary syndrome (within the last 30 days), recent hospitalization (within the last 30 days) due to $\mathrm{HF}$, significant renal dysfunction with estimated glomerular filtration rate (GFR) lower than $25 \mathrm{~mL} / \mathrm{min} / 1.73 \mathrm{~m}^{2}$ and/or on renal replacement therapy or short- or long-term mechanical circulatory support, and a history of cancer with poor prognosis were excluded.

Two hundred and twenty patients who visited the HF outpatient unit of a tertiary hospital of Athens, Greece, during a 5-month period (December 2012 - April 2013) were our study population. According to the abovementioned inclusion and exclusion criteria, only 122 were eligible to participate in the present study, constituting our final study sample. Specifically, 51 patients had a LVEF >45\%, 12 underwent renal replacement therapy, 7 had a recent hospital readmission due to HF symptoms worsening, 3 were currently suffering from cancer with poor prognosis, 2 were younger than 18 years, and finally we had no available data regarding the creatinine and/or hematocrit values for 23 patients. These patients were followed up with regard to their mortality rates, retrospectively, for up to 2 years after their first outpatient visit. Based on patient BMI category, ${ }^{9}$ we assigned patients to four groups: 1) the normal BMI group, with BMI values from 18.5 to $24.9 \mathrm{~kg} / \mathrm{m}^{2}(\mathrm{n}=26)$; 2) the underweight group, with BMI values $\left.\leq 18.4 \mathrm{~kg} / \mathrm{m}^{2}(\mathrm{n}=0) ; 3\right)$ the overweight group, with BMI values from 25 to $29.9 \mathrm{~kg} / \mathrm{m}^{2}(\mathrm{n}=50)$; and 4) the obese group, with BMI values $\geq 30 \mathrm{~kg} / \mathrm{m}^{2}(\mathrm{n}=46)$.

\section{Method \& data collection}

Data collection was performed, retrospectively, in December 2015. For data collection purposes, a structured short questionnaire was created, which included information on the following baseline (first outpatient visit) demographic and clinical variables: patients' gender, age, height and weight, estimated GFR, systolic and diastolic arterial pressure, heart rate, hematocrit, New York Heart Association (NYHA) class, etiology of HF, and echocardiographic findings (LVEF, left ventricular end diastolic diameter, and estimated right atrial pressure). These data were collected through a review of the medical patient records, which was conducted by one of the researchers, the same one each time to ensure the reliability and validity of the data collection process. Patient deaths were investigated during the 2-year follow-up period and were recorded as 1-year and 2-year mortality. BMI was calculated through data on patients' height and weight and specifically using the formula: BMI = weight $(\mathrm{kg}) /[\text { height }(\mathrm{m})]^{2}$.

\section{Statistical analysis}

Categorical and numerical data are expressed as n (\%) and mean [ \pm standard deviation (SD)], respectively. Bivariate analyses were performed using the Mann-Whitney $U$ test, the $\chi^{2}$ test, and the Student's $t$-test. All tests of statistical significance were two-tailed, and $p$-values of less than 0.05 were considered statistically significant. Analyses were conducted using IBM SPSS 21.0 for Windows.

\section{Ethics}

Data collection was conducted after written permission from the ethics committees of both the "Alexandra" General Hospital of Athens, Greece, and the Faculty of Nursing, National and Kapodistrian University of Athens, Greece, were obtained. The requirement of patient consent was 
waived by the hospital ethics committee as the data collection was carried out retrospectively. The investigation was carried out in accordance with the ethical standards of the responsible institutional committee for human experimentation and in accordance with the Helsinki Declaration of 1975, as revised in 2013. Precautions were taken to protect the privacy of research subjects and the confidentially of their personal information.

\section{Results}

The mean $( \pm \mathrm{SD})$ patients' age was $62.8( \pm 1.1)$ years, and the majority of them were males $(79.5 \%)$. Ischemic heart disease (IHD) was the most common etiology (45.9\%) of HF, and, totally, 96 patients $(78.7 \%)$ were overweight and obese. Additionally, $62 \%$ of our sample suffered from HF NYHA class II, and the mean $( \pm \mathrm{SD})$ LVEF value was $31.1( \pm 0.7) \%$.

We had no underweight patients in our study and, as shown Table 1, the 3 remaining patient groups were not similar regarding the baseline clinical characteristics. Specifically, normal BMI patients had significantly higher prevalence of IHD as HF etiology $(53.8 \%$ vs $37 \%, p=0.045)$ and significantly lower values of LVEF $(31.02 \pm 1.53 \%$ vs $34.36 \pm 1.16 \%$, $p=0.024)$, hematocrit $(38.74 \pm 0.87 \%$ vs $41.40 \pm 0.6 \%$, $p=0.007)$, and systolic arterial pressure $(103.3 \pm 2.89 \mathrm{mmHg}$ vs $112.0 \pm 2.9 \mathrm{mmHg}, p=0.044)$ compared with obese group. Additionally, obese patients had significantly higher LVEF values $(34.36 \pm 1.16 \%$ vs $29.16 \pm 0.93 \%, p=0.001)$ compared with overweight group, and overweight patients had greater systolic arterial pressure values $(107.40 \pm 1.52 \mathrm{mmHg}$ vs $103.30 \pm 2.89 \mathrm{mmHg}, p=0.044)$ compared with normal BMI group. Regarding the relationship between NYHA class and BMI category, we found no statistically significant associations. The main baseline demographic and clinical patient characteristics for each group are depicted in Table 1.

Table 2 summarizes the 1- and 2-year patient mortality rates per BMI category. Patients with normal BMI had higher mortality rates at 1 - and 2 years after the first outpatient visit compared with overweight and obese patients. By using bivariate analysis, it seems that obese patients had significantly lower 1-year ( $13 \%$ vs $34.6 \%, p=0.039)$ and 2 -year mortality ( $4 \%$ vs $21.4 \%, p=0.022$ ) compared with those with normal BMI values (Table 3 ).

\section{Discussion}

The main finding of the present study was the significantly lower 1- and 2-year mortality rates of obese patients com-

Table $2 \mathrm{I}$ - and 2-year mortality in each patient group

\begin{tabular}{llll}
\hline Variables & \multicolumn{3}{l}{ BMI group } \\
\cline { 2 - 4 } & Normal & Overweight & Obese \\
\cline { 2 - 4 } & \multicolumn{3}{c}{$\mathbf{n}(\%)$} \\
\hline I-year mortality & $6(21.4)$ & $8(14.8)$ & $2(4)$ \\
2-year mortality & $9(34.6)$ & $13(26)$ & $6(13)$ \\
\hline
\end{tabular}

Abbreviation: BMI, Body Mass Index.

Table I Baseline demographic and clinical patient characteristics in each group

\begin{tabular}{|c|c|c|c|c|c|c|c|c|c|}
\hline Variables & $\begin{array}{l}\text { Normal } \\
(n=26)\end{array}$ & $\begin{array}{l}\text { Overweight } \\
(n=50)\end{array}$ & $p$-value & $\begin{array}{l}\text { Normal } \\
(n=26)\end{array}$ & $\begin{array}{l}\text { Obese } \\
(n=46)\end{array}$ & $p$-value & $\begin{array}{l}\text { Overweight } \\
(n=50)\end{array}$ & $\begin{array}{l}\text { Obese } \\
(n=46)\end{array}$ & $p$-value \\
\hline Gender $^{a}$ & & & $0.38^{b}$ & & & $0.4^{\mathrm{b}}$ & & & $\mathrm{I}^{\mathrm{b}}$ \\
\hline Males & 73 & 82 & & 73 & 80.4 & & 82 & 80.4 & \\
\hline Females & 27 & 18 & & 27 & 19.6 & & 18 & 19.6 & \\
\hline $\mathrm{IHD}$ & 53.8 & 50 & $0.44^{b}$ & 53.8 & 37 & $0.045^{b}$ & 50 & 37 & $0.2 \mathrm{I}^{\mathrm{b}}$ \\
\hline NYHA class ${ }^{\mathrm{a}}$ & & & $0.367^{b}$ & & & $0.366^{\mathrm{b}}$ & & & $I^{*}$ \\
\hline I-II & 73.1 & 83.3 & & 73.1 & 83.3 & & 83.3 & 83.3 & \\
\hline III-IV & 26.9 & 16.7 & & 26.9 & 16.7 & & 16.7 & 16.7 & \\
\hline Age (years) ${ }^{c}$ & $63.7 \pm 2.7$ & $63.5 \pm 1.9$ & $0.66^{\mathrm{d}}$ & $63.73 \pm 2.7$ & $61.7 \pm 1.7$ & $0.4^{\mathrm{d}}$ & $63.5 \pm 1.9$ & $61.7 \pm 1.7$ & $0.48^{\mathrm{e}}$ \\
\hline $\operatorname{LVESD}(\mathrm{mm})^{\mathrm{c}}$ & $64.3 \pm 1.5$ & $66 \pm 1.1$ & $0.37^{e}$ & $64.3 \pm 1.5$ & $64.8 \pm 1.2$ & $0.75^{\mathrm{e}}$ & $66 \pm 1.1$ & $64.8 \pm 1.2$ & $0.46^{\mathrm{e}}$ \\
\hline LVEDD $(\mathrm{mm})^{\mathrm{c}}$ & $5 I \pm 2$ & $52.8 \pm \mathrm{I} .4$ & $0.46^{\mathrm{e}}$ & $51 \pm 2$ & $50 \pm 1.6$ & $0.59^{e}$ & $52.8 \pm 1.4$ & $50 \pm 1.6$ & $0.18^{e}$ \\
\hline $\operatorname{LVEF}(\%)^{c}$ & $3 \mid \pm 1.5$ & $29.2 \pm 0.9$ & $0.29^{d}$ & $3 I \pm I .5$ & $34.4 \pm 1.2$ & $0.024^{d}$ & $29.2 \pm 0.9$ & $34.4 \pm 1.2$ & $0.00 \mathrm{I}^{\mathrm{d}}$ \\
\hline GFR $\left(\mathrm{mL} / \mathrm{min} / \mathrm{I} .73 \mathrm{~m}^{2}\right)^{\mathrm{c}}$ & $65.5 \pm 5.5$ & $66.7 \pm 3.1$ & $0.85^{e}$ & $65.5 \pm 5.5$ & $72.9 \pm 3.2$ & $0.48^{e}$ & $66.7 \pm 3.1$ & $72.9 \pm 3.2$ & $0.16^{\mathrm{e}}$ \\
\hline $\mathrm{Ht}(\%)^{\mathrm{c}}$ & $38.7 \pm 0.9$ & $40.2 \pm 0.6$ & $0.17^{\mathrm{e}}$ & $38.7 \pm 0.9$ & $41.4 \pm 0.6$ & $0.007^{e}$ & $40.2 \pm 0.6$ & $41.4 \pm 0.6$ & $0.16^{\mathrm{e}}$ \\
\hline $\operatorname{SAP}(\mathrm{mmHg})^{\mathrm{c}}$ & $103.3 \pm 2.9$ & $107.4 \pm 1.5$ & $0.044^{d}$ & $103.3 \pm 2.9$ & $112 \pm 2.9$ & $0.012^{\mathrm{d}}$ & $107.4 \pm 1.5$ & $112 \pm 2.9$ & $0.21^{d}$ \\
\hline $\operatorname{DAP}(\mathrm{mmHg})^{\mathrm{c}}$ & $66.5 \pm 1.6$ & $69 \pm 1.1$ & $0.14^{d}$ & $66.5 \pm 1.6$ & $69.3 \pm 1.3$ & $0.22^{\mathrm{d}}$ & $69 \pm 1.1$ & $69.3 \pm 1.3$ & $0.93^{d}$ \\
\hline Heart Rate $(b / \mathrm{min})^{c}$ & $65.5 \pm 1.5$ & $63.6 \pm 1.2$ & $0.32^{\mathrm{d}}$ & $65.5 \pm 1.5$ & $65.9 \pm 1.4$ & $0.84^{d}$ & $63.6 \pm 1.2$ & $65.9 \pm 1.4$ & $0.17^{\mathrm{d}}$ \\
\hline Estimated RAP $\left(\mathrm{cmH}_{2} \mathrm{O}\right)^{c}$ & $8.2 \pm 0.9$ & $6.5 \pm 0.6$ & $0.07^{d}$ & $8.2 \pm 0.9$ & $6.1 \pm 0.4$ & $0.07^{d}$ & $6.5 \pm 0.6$ & $6.1 \pm 0.4$ & $0.9^{d}$ \\
\hline
\end{tabular}

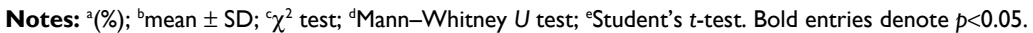

Abbreviations: DAP, Diastolic Arterial Pressure; GFR, Glomerular Filtration Rate; Ht, Hematocrit; IHD, Ischemic Heart Disease; LVEDD, Left Ventricular End Diastolic Diameter; LVEF, Left Ventricular Ejection Fraction; LVESD, Left Ventricular End Systolic Diameter; NYHA, New York Heart Association; RAP, Right Atrial Pressure; SAP, Systolic Arterial Pressure. 
Table 3 Comparison of I- and 2-year mortality among patient groups

\begin{tabular}{|c|c|c|c|c|c|c|c|c|c|}
\hline Variables & $\begin{array}{l}\text { Normal } \\
(n=26)\end{array}$ & $\begin{array}{l}\text { Overweight } \\
(n=50)\end{array}$ & $p$-value & $\begin{array}{l}\text { Normal } \\
(n=26)\end{array}$ & $\begin{array}{l}\text { Obese } \\
(n=46)\end{array}$ & $p$-value & $\begin{array}{l}\text { Overweight } \\
(n=50)\end{array}$ & $\begin{array}{l}\text { Obese } \\
(n=46)\end{array}$ & $p$-value \\
\hline I-year mortality, (\%) & 34.6 & 26 & $0.44^{\mathrm{a}}$ & 34.6 & 13 & $0.039^{a}$ & 26 & 13 & $0.13^{a}$ \\
\hline 2-year mortality, (\%) & 21.4 & 14.8 & $0.54^{\mathrm{a}}$ & 21.4 & 4 & $0.022^{\mathrm{a}}$ & 14.8 & 4 & $0.095^{\mathrm{a}}$ \\
\hline
\end{tabular}

Note: ${ }^{a} \chi^{2}$ test.

pared with normal BMI HF patients. Additionally, we found higher baseline values of LVEF, hematocrit, and systolic arterial pressure and simultaneously decreased occurrence of IHD as the etiology of HF among obese HF patients compared to the patients in the other BMI categories.

As aforementioned, the most important finding of this study was the significantly reduced 1- and 2-year mortality in obese patients suffering from HF. This finding confirms the obesity paradox of HF patients and is in line with several studies from the international literature. By using meta-analysis, Padwal et $\mathrm{al}^{5}$ showed that obese patients had a significantly lower 3-year mortality than those with normal BMI and obesity paradox was present in both those with reduced and those with preserved LVEF. In a recently published systematic review, the authors observed significantly lower mortality rates in patients with increased BMI, according to the results of the 10 studies which were reviewed. ${ }^{19}$ Likewise, a large body of the currently available published research has shown that obese or overweighed patients with $\mathrm{HF}$ are characterized by better survival rates compared with those with ideal BMI. ${ }^{7,20-22}$ However, contrary to the abovementioned findings, some other studies failed to show association between BMI categories and mortality, ${ }^{11-14}$ for example, as highlighted by Colín-Ramírez et al, ${ }^{15}$ normal BMI patients had better survival than obese patients.

Based on the findings of this study, we could claim that the higher values of LVEF and hematocrit among obese HF patients justify the better prognosis seen in these patients. Indeed, the most recently published guidelines of the European Society of Cardiology states that low LVEF and hematocrit values are well-known risk factors for poor prognosis in HF patients. ${ }^{4}$ Likewise, the higher levels of systolic blood pressure among obese group indicate the better tolerance of these patients to antihypertensive drugs and, by extension, a potential improved outcome. ${ }^{9}$

The higher LVEF levels among obese HF patients compared with overweight and normal BMI patients are consistent with other research findings indicating that obese patients maintain a better left ventricular function. ${ }^{7,8,21,23}$ However, Frankenstein et $\mathrm{al}^{12}$ showed that normal BMI patients had a significantly higher LVEF compared with the patients in the rest of the BMI categories. Also, high hematocrit levels in obese HF patients are a well-documented finding in the international literature. ${ }^{21,23-25}$ On the other hand, we failed to associate the renal function with BMI categories, a result that is in line with other studies. Simultaneously, patients' classification according to NYHA system was not associated with BMI categories, contrary to the findings of other studies. ${ }^{8,12,24,26}$ It seems that the relatively small sample size did not allow us to have more statistically significant relationships between the evaluated variables of our study.

Another important finding of our study was the significantly lower occurrence of IHD among obese HF patients, who had decreased long-term mortality rates compared with those of the normal BMI patient group. Although, little is known regarding the potential role of HF etiology on the obesity paradox, we found the study of Zamora et $\mathrm{al}^{27}$ to be in line with our results, as they observed that the obesity paradox was seen in patients with nonischemic HF. In contrast, several other studies have underlined the presence of this phenomenon in large series of HF patients with IHD. ${ }^{28,29}$

Finally, although the present study failed to statistically document the higher long-term mortality rates of overweight and obese patients compared with normal BMI and overweight patients, respectively, these findings are of great clinical significance for the optimal risk stratification of patients with chronic HF.

\section{Study limitations}

The retrospective study design, the small sample size, and the single-center nature of the study limit the generalization of the present findings to the wide population of HF patients, and thus affect its external validity.

\section{Conclusion}

Obese patients with HF have better prognosis and clinical characteristics compared with those with ideal BMI, confirming the hypothesis of obesity paradox. It seems that the better clinical performance of these patients, translating into better LVEF, hematocrit, and systolic blood pressure levels, strongly justifies their longer survival rates.

Based on the abovementioned study limitations and the inherent weaknesses of BMI tool to adequately assess obesity, 
further research with multicenter studies, prospective design, and greater sample size is needed for the future investigation of obesity paradox in HF patients. Despite the presence or absence of this phenomenon, obesity is a well-documented risk factor of $\mathrm{HF}$ and should be treated through a healthy diet and increased physical activity, both of which aim to assist in the maintenance of normal body weight and the avoidance of HF cachexia.

\section{Disclosure}

The authors report no conflicts of interest in this work.

\section{References}

1. Benjamin EJ, Blaha MJ, Chiuve SE, et al. Heart Disease and Stroke Statistics-2017 Update: A Report From the American Heart Association. Circulation. 2017;135(10):e146-e603.

2. Alpert MA, Lavie CJ, Agrawal H, Aggarwal KB, Kumar SA. Obesity and heart failure: epidemiology, pathophysiology, clinical manifestations, and management. Transl Res. 2014;164(4):345-356.

3. Carbone S, Lavie CJ, Arena R. Obesity and heart failure: Focus on the obesity paradox. Mayo Clin Proc. 2017;92(2):266-279.

4. Ponikowski P, Voors AA, Anker SD, et al. 2016 ESC Guidelines for the diagnosis and treatment of acute and chronic heart failure: The Task Force for the diagnosis and treatment of acute and chronic heart failure of the European Society of Cardiology (ESC). Developed with the special contribution of the Heart Failure Association (HFA) of the ESC. Eur J Heart Fail. 2016;18(8):891-975.

5. Padwal R, McAlister FA, McMurray JJ, et al. The obesity paradox in heart failure patients with preserved versus reduced ejection fraction: a meta-analysis of individual patient data. Int J Obes (Lond). 2014;38(8):1110-1114.

6. Sharma A, Lavie CJ, Borer JS, et al. Meta-analysis of the relation of body mass index to all-cause and cardiovascular mortality and hospitalization in patients with chronic heart failure. Am J Cardiol. 2015;115(10):1428-1434.

7. Curtis JP, Selter JG, Wang Y, et al. The obesity paradox: body mass index and outcomes in patients with heart failure. Arch Intern Med. 2005;165(1):55-61.

8. Gastelurrutia P, Pascual-Figal D, Vazquez R, et al. Obesity paradox and risk of sudden death in heart failure results from the MUerte Subita en Insuficiencia cardiaca (MUSIC) study. Am Heart J. 2011;161(1):158-164.

9. Hamzeh N, Ghadimi F, Farzaneh R, Hosseini SK. Obesity, heart failure, and obesity paradox. J Tehran Heart Cent. 2017;12(1):1-5.

10. Lavie CJ, Sharma A, Alpert MA, et al. Update on obesity and obesity paradox in heart failure. Prog Cardiovasc Dis. 2016;58(4):393-400.

11. Kistorp C, Faber J, Galatius S, et al. Plasma adiponectin, body mass index, and mortality in patients with chronic heart failure. Circulation. 2005;112(12):1756-1762.

12. Frankenstein L, Zugck C, Nelles M, Schellberg D, Katus HA, Remppis BA. The obesity paradox in stable chronic heart failure does not persist after matching for indicators of disease severity and confounders. Eur J Heart Fail. 2009;11(12):1189-1194.
13. Schwartzenberg S, Benderly M, Malnick S, George J, Goland S. The "obesity paradox": does it persist among Israeli patients with decompensated heart failure? A subanalysis of the Heart Failure Survey in Israel (HFSIS). J Card Fail. 2012;18(1):62-67.

14. Horwich TB, Broderick S, Chen L, et al. Relation among body mass index, exercise training, and outcomes in chronic systolic heart failure. Am J Cardiol. 2011;108(12):1754-1759.

15. Colín-Ramírez E, Orea-Tejeda A, Castillo-Martínez L, et al. Malnutrition syndrome, but not body mass index, is associated to worse prognosis in heart failure patients. Clin Nutr. 2011;30(6):753-758.

16. Izawa KP, Watanabe $\mathrm{S}$, Oka $\mathrm{K}$, et al. Usefulness of step counts to predict mortality in Japanese patients with heart failure. Am J Cardiol. 2013;111(12):1767-1771.

17. Izawa KP, Watanabe S, Hinaro Y, et al. The relation between Geriatric Nutritional Risk Index and muscle mass, muscle strength, and exercise capacity in chronic heart failure patients. Int J Cardiol. 2014;177(3):1140-1141.

18. Izawa KP, Watanabe $\mathrm{S}, \mathrm{Oka} \mathrm{K}$, et al. Differences in maximum phonation time based on body mass index in chronic heart failure patients. Int $J$ Cardiol. 2015;182:200-202.

19. Oga EA, Eseyin OR. The obesity paradox and heart failure: A systematic review of a decade of evidence. J Obes. 2016;2016:9040248.

20. Zafrir B, Goren Y, Salman N, Amir O. Comparison of body mass index and body surface area as outcome predictors in patients with systolic heart failure. Cardiol J. 2015;22(4):375-381.

21. Shah R, Gayat E, Januzzi JL Jr, et al. Body mass index and mortality in acutely decompensated heart failure across the world: a global obesity paradox. J Am Coll Cardiol. 2014;63(8):778-785.

22. Fonarow GC, Srikanthan P, Costanzo MR, Cintron GB, Lopatin M; ADHERE Scientific Advisory Committee and Investigators. An obesity paradox in acute heart failure: analysis of body mass index and inhospital mortality for 108,927 patients in the Acute Decompensated Heart Failure National Registry. Am Heart J. 2007;153(1):74-81.

23. Wu AH, Eagle KA, Montgomery DG, Kline-Rogers E, Hu YC, Aaronson KD. Relation of body mass index to mortality after development of heart failure due to acute coronary syndrome. Am J Cardiol. 2009;103(12): 1736-1740.

24. Takiguchi M, Yoshihisa A, Miura S, et al. Impact of body mass index on mortality in heart failure patients. Eur J Clin Invest. 2014;44(12): 1197-1205.

25. Nochioka K, Shiba N, Kohno H, Miura M, Shimokawa H. Both high and low body mass indexes are prognostic risks in Japanese patients with chronic heart failure: implications from the CHART study. J Card Fail. 2010;16(11):880-887.

26. Puig T, Ferrero-Gregori A, Roig E, et al. Prognostic value of body mass index and waist circumference in patients with chronic heart failure (Spanish REDINSCOR Registry). Rev Esp Cardiol (Engl Ed). 2014;67(2):101-106.

27. Zamora E, Lupón J, de Antonio M, et al. The obesity paradox in heart failure: is etiology a key factor? Int J Cardiol. 2013;166(3):601-605.

28. Lavie CJ, Milani RV, Artham SM, Patel DA, Ventura HO. The obesity paradox, weight loss, and coronary disease. AmJMed. 2009;122(12):1106-1114.

29. Romero-Corral A, Montori VM, Somers VK, et al. Association of bodyweight with total mortality and with cardiovascular events in coronary artery disease: a systematic review of cohort studies. Lancet. 2006;368(9536):666-678.
Pragmatic and Observational Research

\section{Publish your work in this journal}

Pragmatic and Observational Research is an international, peer-reviewed, open access journal that publishes data from studies designed to reflect more closely medical interventions in real-world clinical practice compared with classical randomized controlled trials (RCTs). The manuscript management system is completely online and includes a very quick and fair peer-review

\section{Dovepress}

system. Visit http://www.dovepress.com/testimonials.php to read real quotes from published authors. 